\title{
Erratum to: Maintenance with rituximab is safe and not associated with severe or uncommon infections in patients with follicular lymphoma: results from the phase IIIb MAXIMA study
}

\author{
Mathias Witzens-Harig • Robin Foá • Alice Di Rocco • Guy van Hazel • \\ Dalton F. A. Chamone • Jacob M. Rowe • Luca Arcaini • Irina Poddubnaya • \\ Anthony D. Ho • Valentina Ivanova • Andrej Vranovsky $•$ Dan Thurley $\cdot$ Stephan Oertel
}

Published online: 4 July 2014

(C) Springer-Verlag Berlin Heidelberg 2014

\section{Erratum to: Ann Hematol}

DOI 10.1007/s00277-014-2103-3

The original version of this article inadvertently contained an error in the footnote of Table 1 (Patient disposition). A total of 16 patients discontinued prematurely due to treatment-related toxicity as shown correctly in the original table, but the details of these discontinuations shown in the footnote did not account for all 16 patients. The corrected footnote is as follows:

The online version of the original article can be found at http://dx.doi.org/ 10.1007/s00277-014-2103-3.

\footnotetext{
M. Witzens-Harig · A. D. Ho

University of Heidelberg, Heidelberg, Germany

R. Foá $\cdot$ A. Di Rocco

Sapienza University of Rome, Rome, Italy

G. van Hazel

University of Western Australia, Perth, Australia

D. F. A. Chamone

Disciplina de Hematologia do Hospital das Clínicas da FMUSP, São

Paulo, Brazil

J. M. Rowe

Israel Institute of Technology, Haifa, Israel

L. Arcaini

Fondazione IRCCS Policlinico San Matteo and University of Pavia,

Pavia, Italy
}

Hypogammaglobulinemia $(n=2)$; bacterial arthritis $(n=1)$; idiopathic thrombocytopenic purpura $(n=1)$; chronic active hepatitis $(n=1)$; respiratory failure $(n=1)$; allergy to arthropod bite $(n=1)$; pneumonia $(n=1)$; prostate cancer $(n=1)$; bronchitis $(n=1)$; cardiomyopathy $(n=1)$; febrile neutropenia $(n=1)$; salmonellosis $(n=1)$; blood immunoglobulin M increased $(n=1)$; lymphocyte count decreased $(n=1)$; cerebrovascular accident $(n=1$ : patient was not recorded as a discontinuation but last received study drug on 30 August 2007 and their AEs on/after that date were recorded as hypertensive crisis grade 1 and the grade 4 SAE of cerebrovascular accident).

\author{
I. Poddubnaya \\ N. N. Blokhin Cancer Research Center, Moscow, Russia \\ V. Ivanova \\ Botkin Municipal Clinical Hospital, Moscow, Russia
}

\author{
A. Vranovsky \\ National Cancer Institute, Bratislava, Slovakia \\ D. Thurley \\ Roche Products Pty Ltd, Dee Why, Australia \\ S. Oertel \\ F. Hoffmann-La Roche Ltd., Basel, Switzerland \\ M. Witzens-Harig $(\bowtie)$ \\ Department of Hematology and Oncology, University Hospital \\ Heidelberg, Im Neuenheimer Feld 410, 69120 Heidelberg, Germany \\ e-mail: Mathias.Witzens-Harig@med.uni-heidelberg.de
}

